\title{
Microscopic Anatomy of the Pulmonary Vascular Bed in the Cat Lung
}

\author{
JoHANNES A. G. RHODIN \\ Department of Anatomy, University of Michigan Medical School, Ann Arbor, Michigan 48109
}

Received September 17, 1976

\begin{abstract}
The pulmonary microcirculation of the cat was analyzed by light and electron microscopy. In order to establish the precise structure and ultrastructure of the components of the vascular wall of each segment, special efforts were made to identify positively the pulmonary arterioles and venules by tracing their connection to small pulmonary arteries and veins, respectively. Also, the pulmonary arterioles and venules were studied with respect to their relationship to the alveolar capillary network via the precapillary sphincter areas and the postcapillary venules. It was confirmed that the small pulmonary arteries, arterioles, and precapillary sphincter areas are provided with smooth muscle cells which are present up to the point where the pulmonary capillaries branch out, although the number of smooth muscle cells decreases gradually toward the capillary bed. Cholinergic and noradrenergic nerves accompany all arterial segments. The capillary network described by many investigators in several mammalian species was studied only to the extent that a three-dimensional conceptualization could be obtained. With respect to the postcapillary venules and pulmonary venules, it was discovered that, in the cat lung, true smooth muscle cells, albeit widely scattered, are present in these segments of the pulmonary microcirculation. These smooth muscle cells display extensive areas of myoendothelial junctions. That is, the cell membranes of the endothelial cells and the smooth muscle cells make contact without an intervening basal lamina. Some myocndothelial junctions were identified also in the arterioles and precapillary sphincter areas. However, they were few in number and had points of only limited membrane contact. The functional implications of these findings are discussed in terms of possible regulatory influence on the pulmonary microcirculation and hypothetical role in the development of pulmonary hypertension.
\end{abstract}

\section{INTRODUCTION}

The pulmonary capillaries and their distribution in the alveolar walls and interalveolar septa have been analyzed in great detail in a variety of mammalian species by light and electron microscopy (Divertie and Brown, 1964; Weibel and Knight, 1964; Sobin et al., 1966; Schneeberger-Keeley and Karnovsky, 1968; Fung and Sobin, 1969; Sobin et al., 1970; Rosenquist et al., 1973; Weibel, 1969, 1973). On the other hand, pulmonary arterioles and venules which supply and drain the alveolar capillary bed have received only limited attention with electron-microscopic techniques (Policard $e t$ al., 1965; Fillenz, 1966, 1970; Rhodin, 1974), although they have been the subject of several light-microscopic investigations (von Hayek, 1940; Merkel, 1940; Macklin, 1945; Verloop, 1949; Hirsch, 1957; Krahl, 1959, 1962; Pump, 1961; Best and Heath, 1961; Alexander and Jensen, 1963).

The purpose of this investigation was to analyze and compare the ultrastructure of small pulmonary arteries and veins, as well as arterioles and venules, in order to further elucidate the structural components of the vascular wall which may participate in a 
control and regulation of the blood flow to and from the alveolar capillaries. During this analysis, it became obvious that a pictorial and three-dimensional conceptualization would be necessary in order to fully visualize and appreciate the architecture of the microvasculature of the pulmonary alveoli of the cat lung. As a result, several diagrams materialized (Figs. 4-6). However, these drawings are not based on actual reconstructions. Nevertheless, they give a fair representation of the density and distribution of the pulmonary capillaries and the approach of the arterioles and venules to this capillary bed in the cat lung.

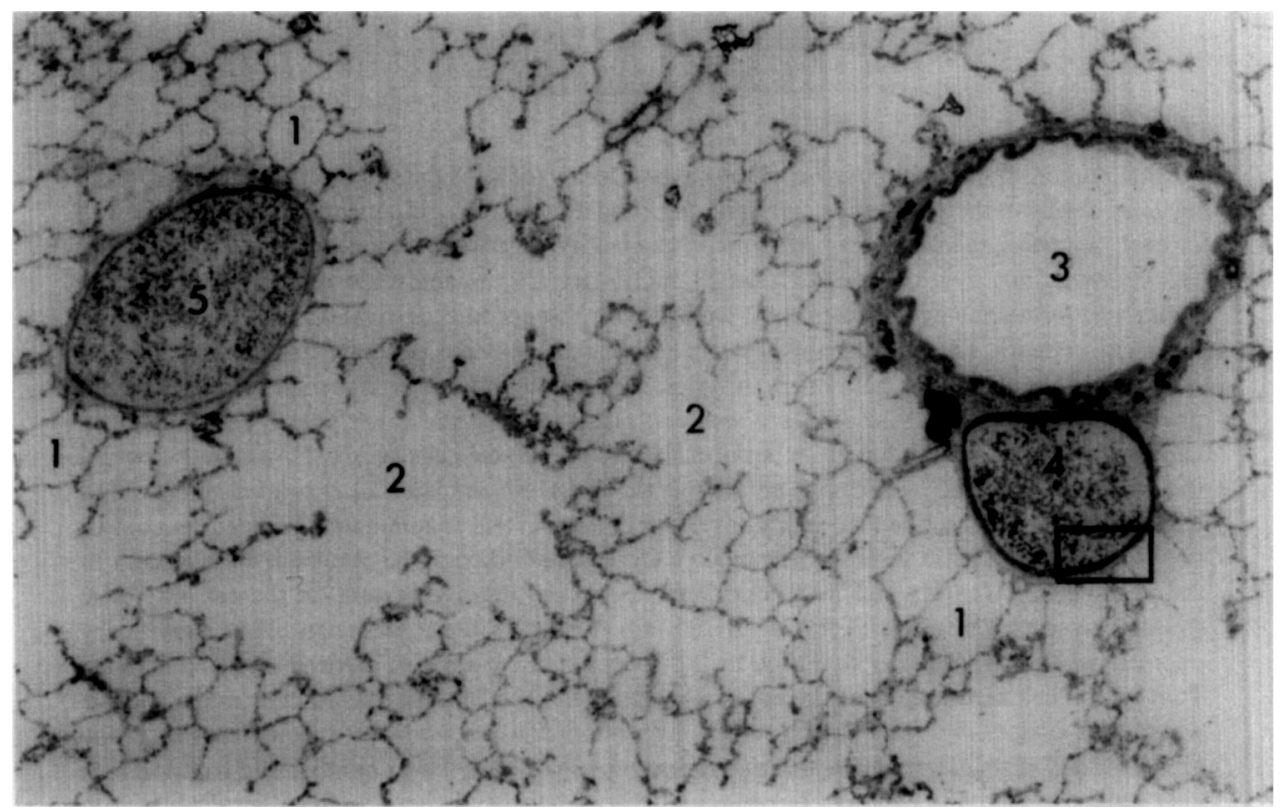

Fig. 1. Light micrograph of the cat pulmonary parenchyma with alveoli (1), alveolar sacs (2), bronchiole (3), small pulmonary artery (4), and small pulmonary vein (5). Observe the classical arrangement, where the pulmonary artery is close to the bronchiole and the pulmonary vein occurs singly within the parenchyma. Average luminal diameter of the pulmonary artery is $300 \mu \mathrm{m}$ and of the pulmonary vein about $450 \mu \mathrm{m}$. The area corresponding to the small rectangle is enlarged in Fig. 2. Cat, L.M. $\times 51$.

For excellent reviews and summary articles of structural and functional aspects of the pulmonary circulation, consult Daly and Hebb (1966), Comroe (1966), Liebow and Smith (1968), Fishman and Hecht (1969), Policard and Galy (1970), Waaler (1971), Lauweryns (1971).

Fig. 2. Segment of cross-sectioned small pulmonary artery (1) with an average luminal diameter of about $300 \mu \mathrm{m}$. The thickness of the intima and the media (2) averages $16 \mu \mathrm{m}$, the adventitia (3) about 12 $\mu \mathrm{m}$. Note alveolar capillaries (4) protruding into the lumen of the pulmonary alveoli (5). The area corresponding to the rectangle is enlarged in Fig. 3. Cat, E.M. $\times 595$.

Fig. 3. Detail of the wall of a small pulmonary artery. The lumen of the artery (1) is lined by squamous endothelial cells (2) which border on an inner elastic lamina (3). The media consists of five to six layers of rather densely packed smooth muscle cells (4) with bundles of collagen fibers (5) in between. There is an indistinct outer elastic lamina (6) which forms the limiting border to the adventitia with its fibroblast processes (7) and bundles of collagen fibers (8). A Schwann cell (9) ensheathes nonmyelinated nerve processes (10), containing both dense-core (noradrenergic) and "clear" (cholinergic) vesicles. Cat, L.M. $\times 8091$. 

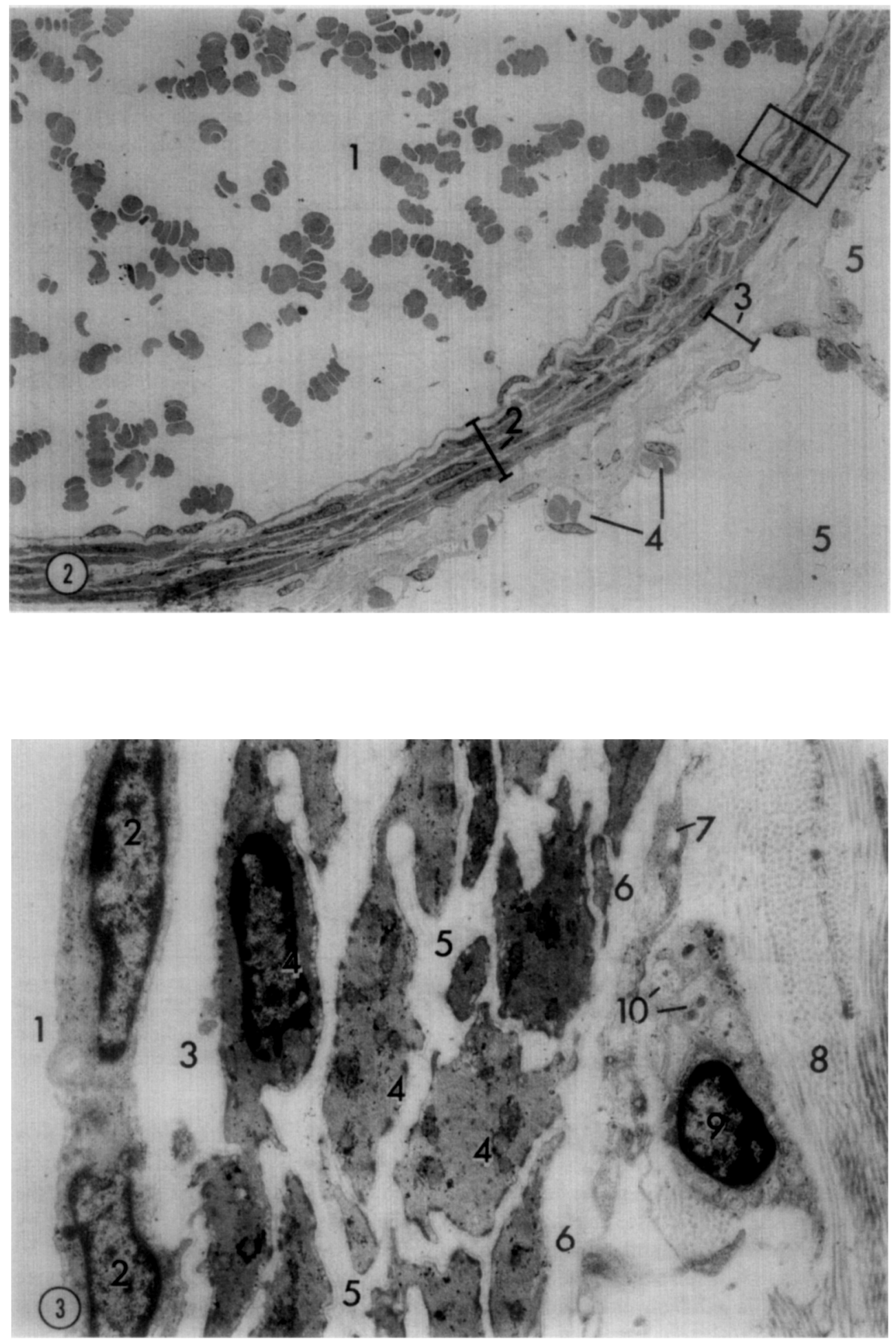


\section{MATERIALS AND METHODS}

In the present analysis, two mature cats were used. Samples were taken from the lowest parts of the lobes in both lungs. The cats were anesthetized by intravenous injection of Nembutal (sodium pentobarbital). A $3 \%$ solution of phosphate-buffered

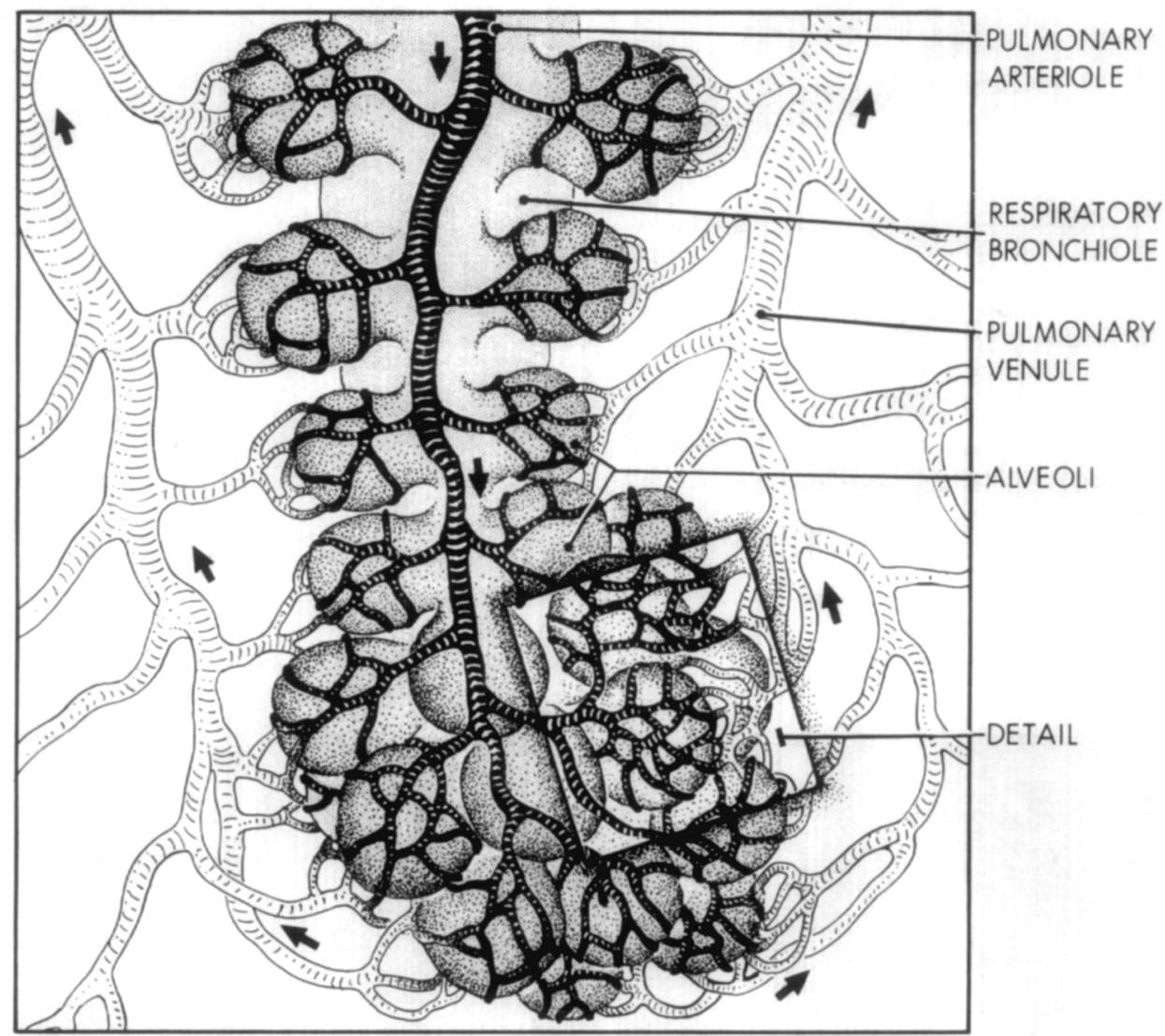

Fig. 4. Diagram of the microcirculatory bed of the respiratory bronchiole, alveolar sac, and individual pulmonary alveoli. The small pulmonary artery or arteriole closely accompanies the airways, and abruptly sends out short terminal arterioles (precapillary sphincter area) which supply the capillary beds of one or several alveoli. The pulmonary venules drain the area and traverse the pulmonary parenchyma at some distance away from the respiratory unit. The rectangular area is enlarged in Fig. 5.

glutaraldehyde was slowly administered down the trachea. The cats were secured to a board on their back with legs spread out. The board was then raised to an almost vertical position and the glutaraldehyde was continuously administered for $30 \mathrm{~min}$, the total amount of fluid used averaging $200 \mathrm{ml}$. The lungs were then rapidly exposed by opening the rib cage, and small pieces of lung were removed and postosmicated for 30 min in a $1 \%$ phosphate-buffered solution of osmium tetroxide. Specimens were dehydrated in ethanol, embedded in Epon, sectioned on a Huxley microtome, and examined in a Siemens Elmiskop $1 \mathrm{~A}$ transmission electron microscope. 


\section{RESULTS}

\section{General}

During an analysis by means of electron microscopy, it is of extreme importance to know which type of pulmonary vessel is being investigated. A technique, extensively utilized in a recent analysis of all mammalian tissues (Rhodin, 1974), was employed also in this investigation, whereby the area is first identified grossly under the light

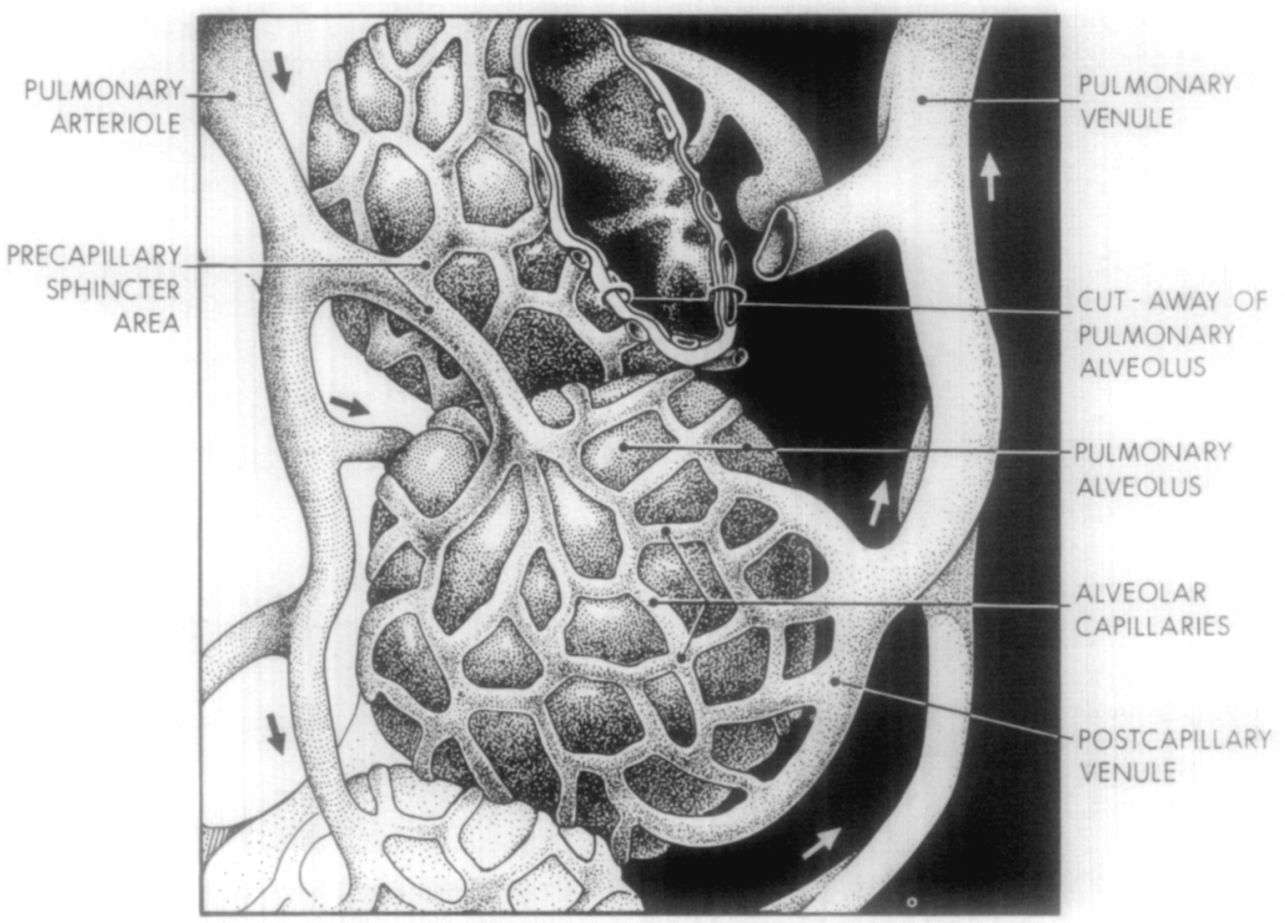

FIG. 5. Three-dimensional conceptualization of the pulmonary microcirculatory bed, based on the present analysis of the cat lung by light and electron microscopy. The precapillary sphincter areas of the pulmonary arteriole may supply several alveoli, and there are several postcapillary venules draining the same alveolar capillary network. In reality, the density of the alveolar capillaries is even greater than that indicated. Note that the various segments of the blood vessels are shown essentially as they would appear in a luminal cast preparation, and the connective tissue cells and fibers of the interalveolar septa have been omitted in the drawing in order to depict with greater clarity the way in which the arterial and venous vessels approach the alveoli.

microscope, and subsequently a detailed analysis is made of a selected part of this area by means of low, medium, and high magnifications in the electron microscope (Figs. 7$10,19-23$ ).

During the investigation of pulmonary blood vessels, their immediate proximity to bronchi, bronchioles, and respiratory bronchioles facilitated their positive identification as arterial pulmonary vessels (Figs. 1 and 4). On the other hand, blood vessels occurring singly without immediate juxtaposition to respiratory passages were identified as pulmonary venous blood vessels (Figs. 1 and 19). Arterioles and venules were 
classified as such only if they could be traced back to a larger pulmonary vessel, already classified according to the above technique, or if they were known to have been connected to an alveolar capillary network by analysis of serial sections.

\section{Small Pulmonary Arteries}

The small pulmonary arteries of the cat lung range in size between 100 and $500 \mu \mathrm{m}$ and are of the muscular type. This means that they have a distinct inner elastic lamina,

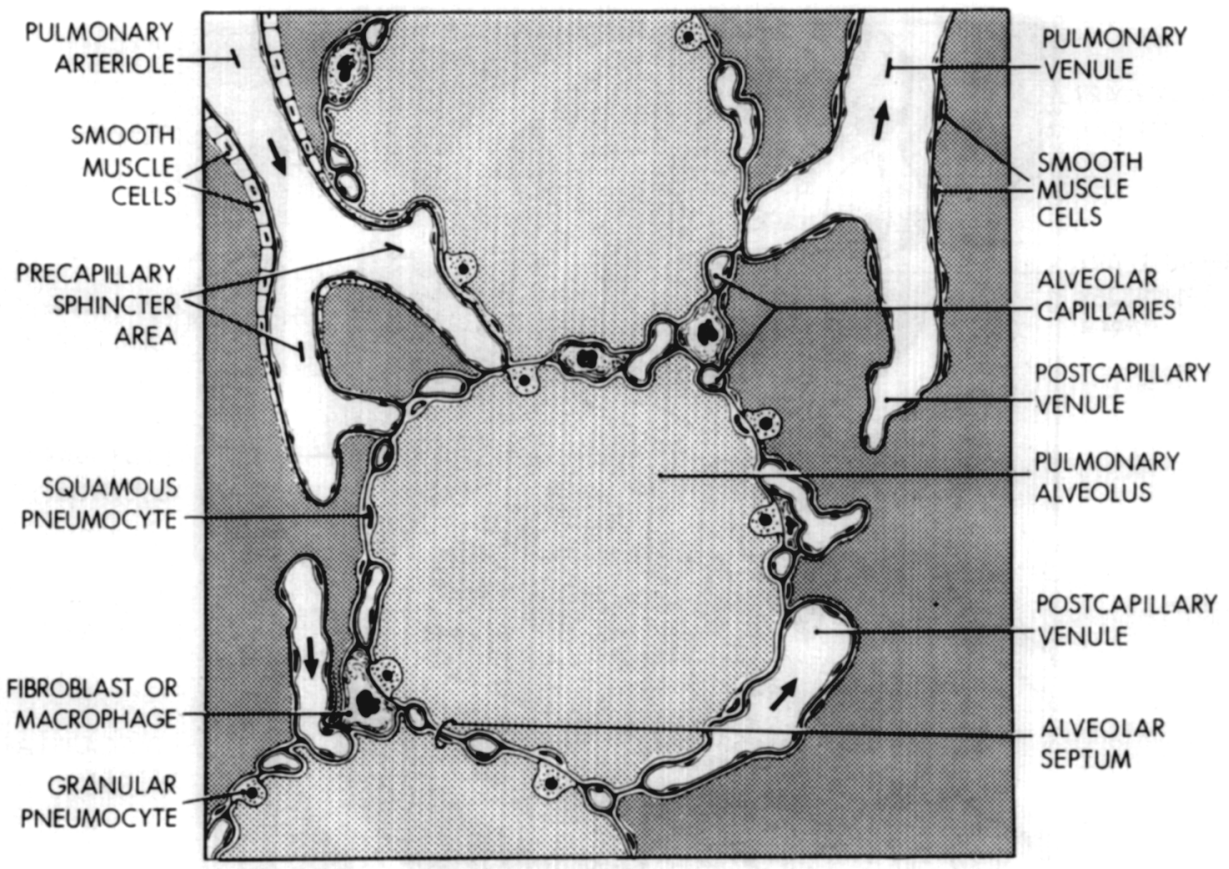

FIG. 6. The three-dimensional view of the microvascular bed seen in Fig. 5 has been translated into a two-dimensional concept in Fig. 6 to facilitate an understanding of how arterioles, capillaries, and venules constitute an integral part of the interalveolar septa. The drawing is a highly simplified version of what really exists. Note the relative density of smooth muscle cells in relation to the arteriolar vessels, and the spacing of smooth muscle cells in relation to the postcapillary venules and pulmonary venules. Some, but not all, connective tissue cells are indicated in the interalveolar septa. They have been left out in relation to arterial and venous vessels.

and a vague indication of an external elastic lamina (Figs. 2 and 3). The intima consists of only a single layer of low cuboidal or squamous endothelial cells. These cells contain a small number of specific endothelial granules (Weibel and Palade, 1964), many

FIGS. 7, 8, AND 9. This demonstrates the positive identification of a pulmonary arteriole (1) which emerges at right angles from a small pulmonary artery (2). The artery is seen in cross-section, and is located near a bronchiole (3). The pulmonary artery is the same as that seen in Fig. 1, but here is sectioned at a different level. This series also demonstrates the value of using toluidine-stained thick sections of Eponembedded material (Figs. 7 and 8) for localization of the pulmonary arteriole, followed by lowmagnification electron microscopy of the same area (Fig. 9). Other structures present are pulmonary alveoli (4), fat cells (5), interalveolar septa (6), and terminal arterioles (precapillary sphincter area) (7). Arrow indicates direction of blood flow. C at lung; Fig. 7, L.M. $\times 58$; Fig. 8, L.M. $\times 233$; Fig. 9, E.M. $\times 519$. 

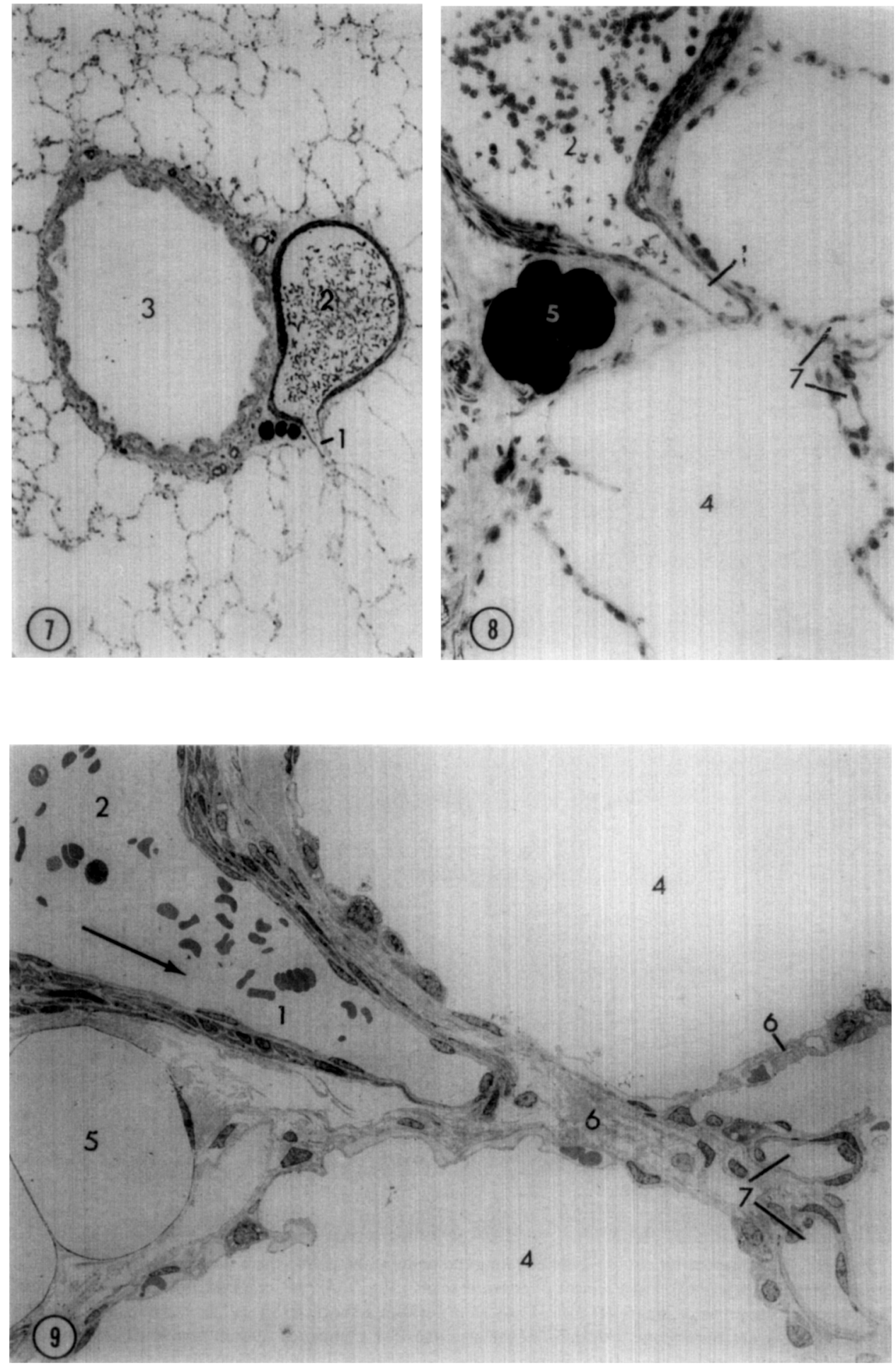


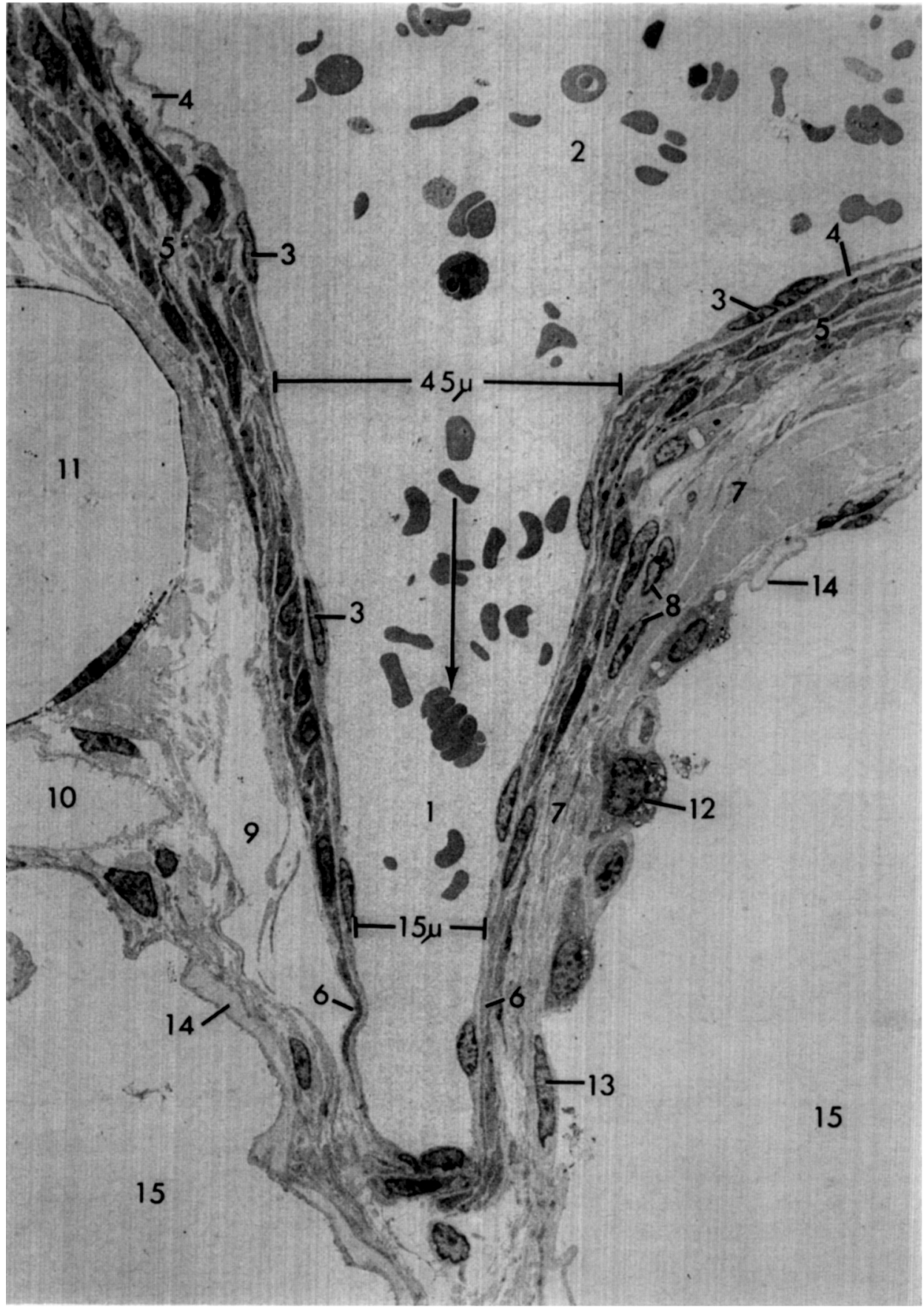

Fig. 10. Pulmonary arteriole (1) sectioned longitudinally at the point where it emerges abruptly from a small pulmonary artery (2). Enlargement of arteriole seen in Fig. 9. Arrow indicates direction of blood flow. The lumen of the arteriole tapers off from 45 to $15 \mu \mathrm{m}$ within a short distance. The endothelial cells (3) of the small artery are continuous with those of the arteriole. The number of smooth muscle cell (5) layers of the artery (four to five layers) is soon reduced to one to two layers in the arteriole (6), and the thickness of 


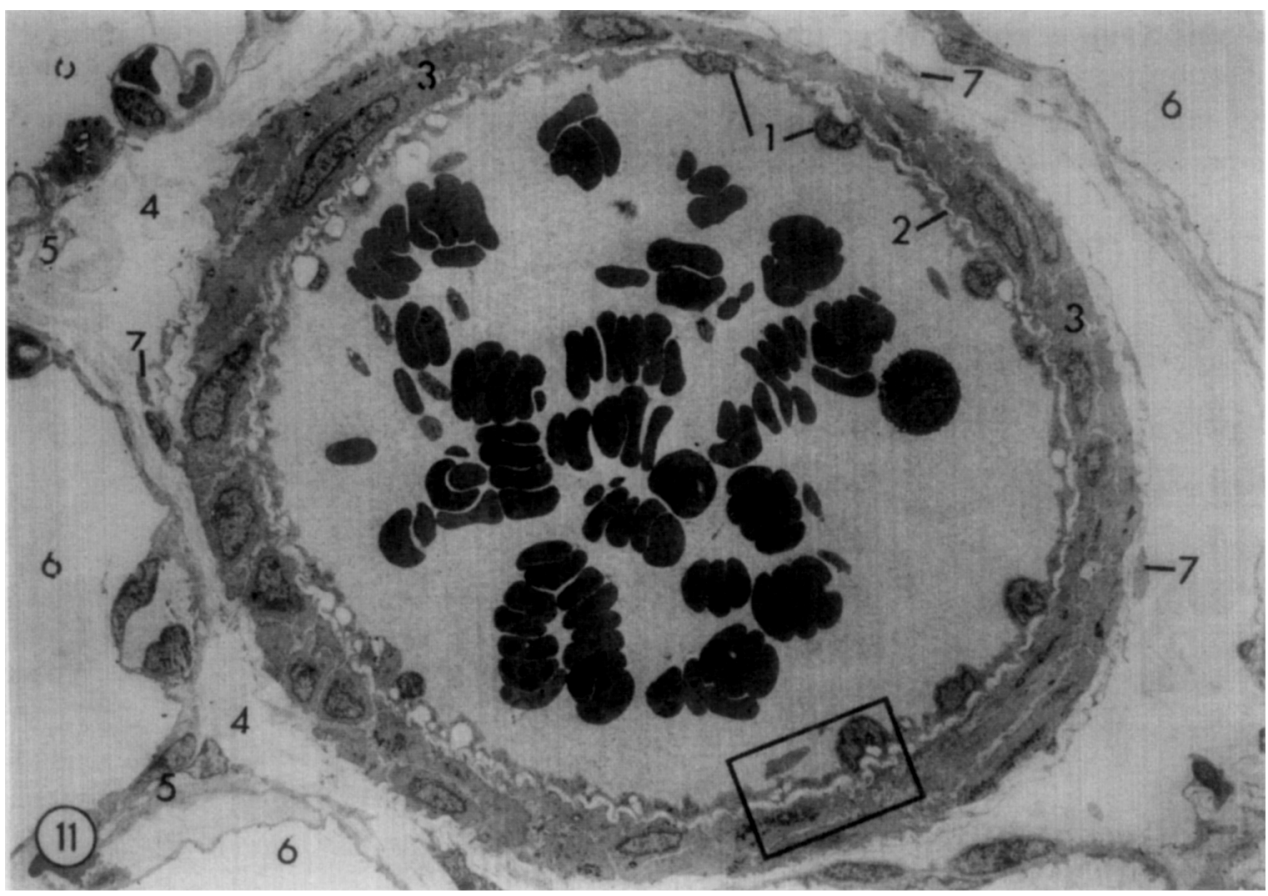

FIG. 11. Cross-section of pulmonary arteriole, situated close to a respiratory bronchiole. Luminal diameter is about $65 \mu \mathrm{m}$. This demonstrates many of the features seen in the longitudinal section of an arteriole in Fig. 10. The arteriole is slightly constricted, judged by the luminal protrusions of some endothelial cells (1) and the wavy appearance of the delicate inner elastic lamina (2). The media (3) consists of one to two layers of smooth muscle cells arranged spirally. The adventitia (4) is thin and delicate, blending with the collagenous and elastic fibers of the septa (5) between the pulmonary alveoli (6). Nonmyelinated nerves (7) can be identified positively at higher magnification. Cat, E.M. $\times 1116$.

surface vesicles, and a rich supply of microfilaments. The media is made up of smooth muscle cells, arranged circularly and/or spirally, consisting of five to eight layers in the larger arteries, and two to three layers in the smaller arteries. The smooth muscle cells make numerous contacts with adjacent smooth muscle cells of the same layer, as well as of other muscle layers. The adventitia is very thin and consists mostly of meshed collagenous and elastic fibers, mixed with a limited number of fibroblasts. There are nonmyelinated nerve fibers and accompanying Schwann cells present in the adventitia. The axons display bead-like swellings which contain both dense-core and clear vesicles.

\section{Pulmonary Arterioles}

Arbitrarily, we have chosen to refer to branches which come off the pulmonary arteries and have a diameter of less than $100 \mu \mathrm{m}$ as pulmonary arterioles. Blood vessels

the adventitia (7) and elastica interna (4) is similarly reduced. Schwann cells (8) carrying nonmyelinated nerves are present in the adventitia. The connective tissue fibers of the adventitia occasionally show imperfect preservation (9). Other structures in the vicinity are lymphatic capillary (10), fat cell (11), granular (12), and squamous (13) pneumocytes, and blood capillaries (14) lining the pulmonary alveoli (15). Note: The identification of the above structures is based on an analysis of this region at considerably higher magnification. Cat, E.M. × 1023 (slightly enlarged from Fig. 9). 
of this diameter either branch from larger arteries directly at about $90^{\circ}$, in which case they taper off rapidly before the precapillary sphincter area, or constitute the ends of the pulmonary arterial system. In this instance, they are most often located near respiratory bronchioles or alveolar ducts (Figs. 7-11).

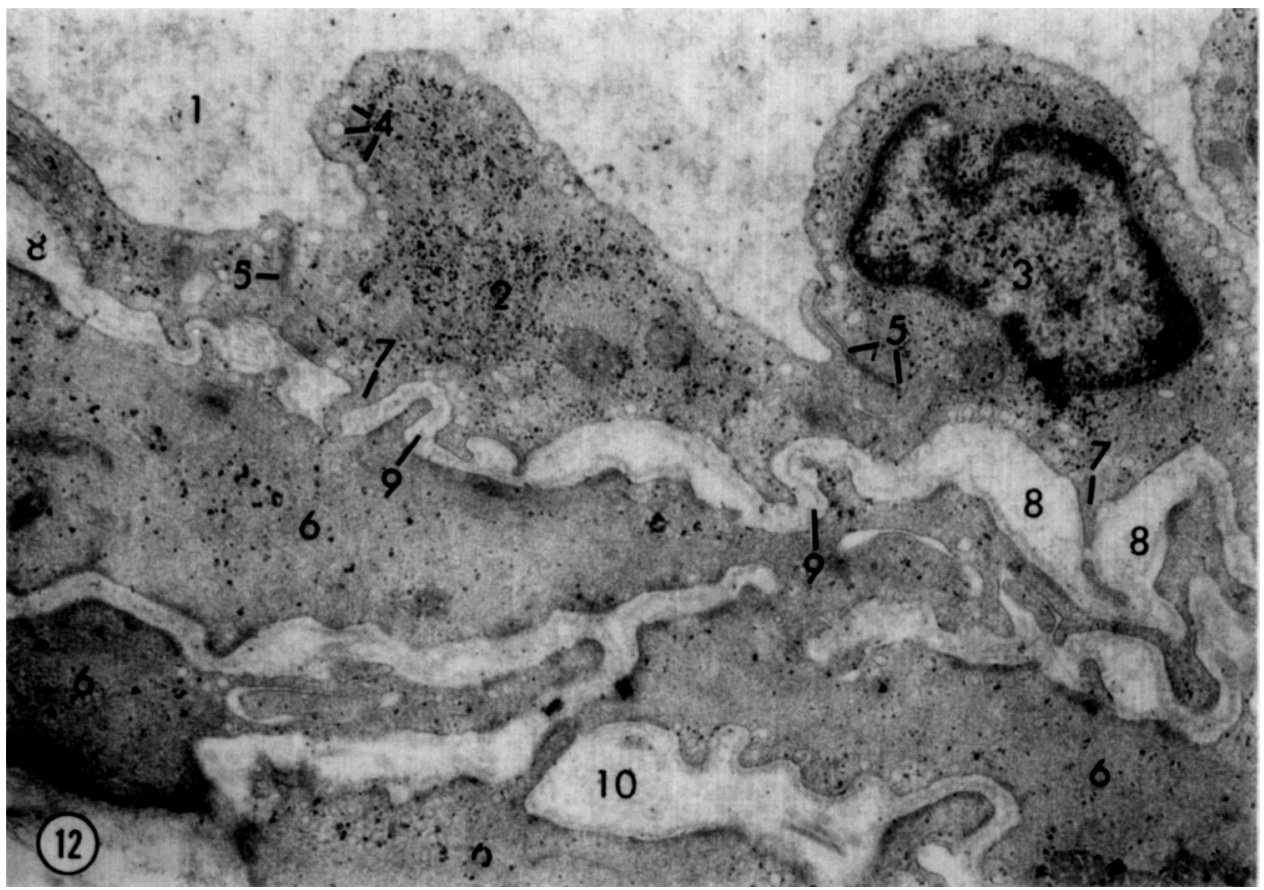

FIG. 12. Detail of a slightly constricted arteriole. This corresponds to an area similar to the rectangle in Fig. 11. The cytoplasm of the endothelial cells protrudes into the lumen of the arteriole (1). The cytoplasm contains ribosomes (2), a nucleus (3), and pinocytotic surface vesicles (4). Adjacent cells form areas of junctional complexes (5). The smooth muscle cells (6) are highly branched. They are invested by a thin external lamina and provided with small cell processes which contact neighboring smooth muscle cells. Occasional narrow processes of the endothelial cells (7) establish myoendothelial junctions across the area beneath the endothelium. This area contains a mixture of elastic components (8) and a delicate basal lamina (9) which appears to be present only in some areas. The narrow space between the smooth muscle cells contains some collagenous fibrils (10). Cat, E.M. $\times 15,810$.

The pulmonary arterioles have an intima which consists of squamous endothelial cells, the ultrastructure of which is similar to that of the endothelial cells of the small pulmonary arteries (Fig. 12). The endothelial cells are separated from the media by a basal lamina which is reinforced by some longitudinally arranged elastic fibers. The smooth muscle cells form two to three layers of interconnected cells, arranged both

Fig. 13. Branches of terminal arteriole (precapillary sphincter area). Enlargement of the same vessels seen in Fig. 9. The wall consists of endothelium (1) and one layer of smooth muscle cells (2). Cat, E.M. $\times 8370$.

FIG. 14. Detail of the wall of a terminal arteriole. The endothelial cells are elongated with a flattened nucleus (1) and cytoplasm. The smooth muscle cells show frequent branchings (2). A basal lamina with some elastic components (3) is present. The arteriole is accompanied by nonmyelinated nerve fibers (4) in the perivascular connective tissue, containing dense-core and clear vesicles, generally accepted as an indication of the nature of the nerves as being both noradrenergic and cholinergic. Cat, E.M. $\times 29,760$. 
circularly and spirally. The adventitia is very narrow, consisting of a thin layer of intertwined collagenous and elastic fibers (Fig. 11). Nerve fibers are present in the adventitia, displaying both dense-core and clear vesicles in their axoplasril.
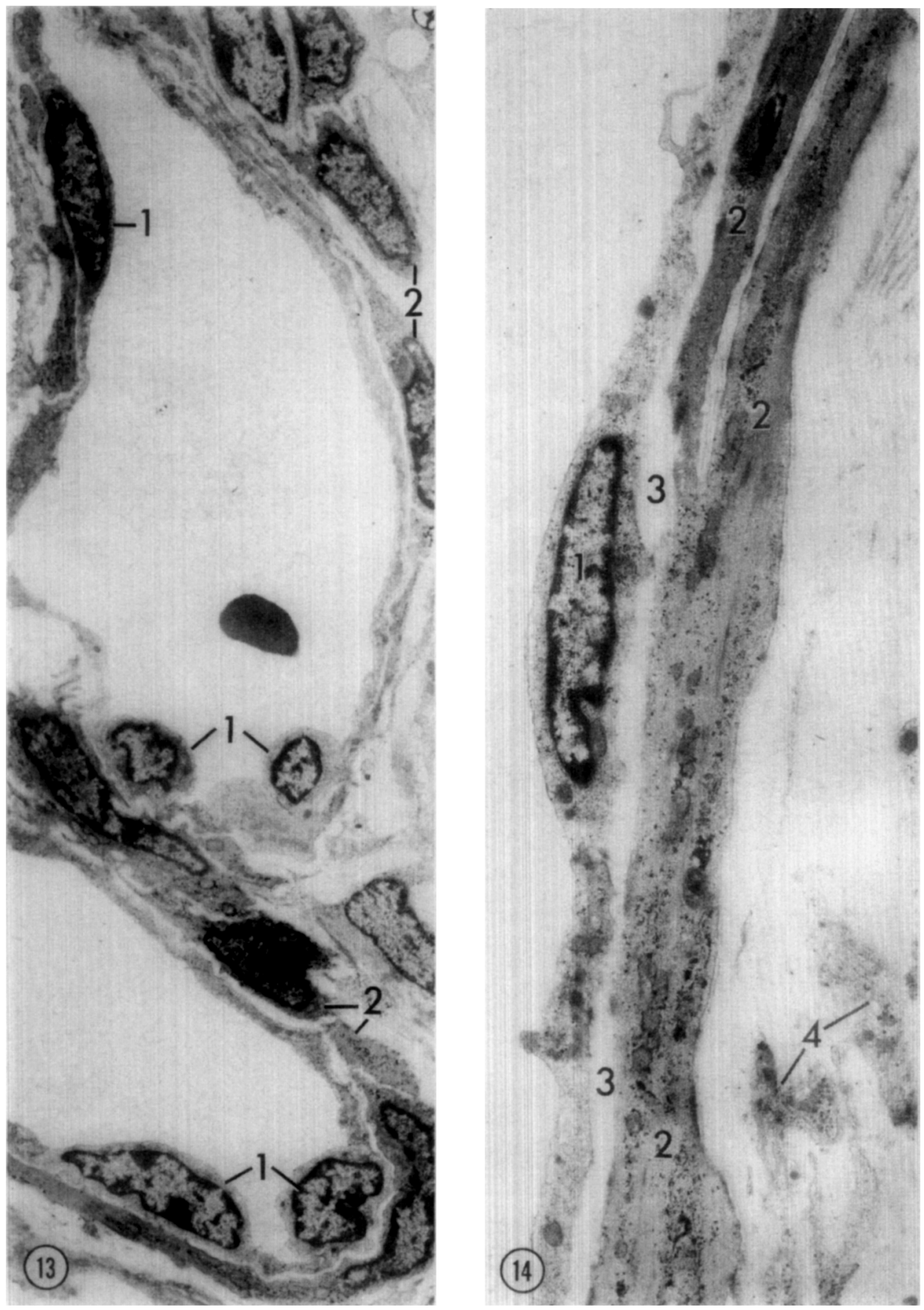


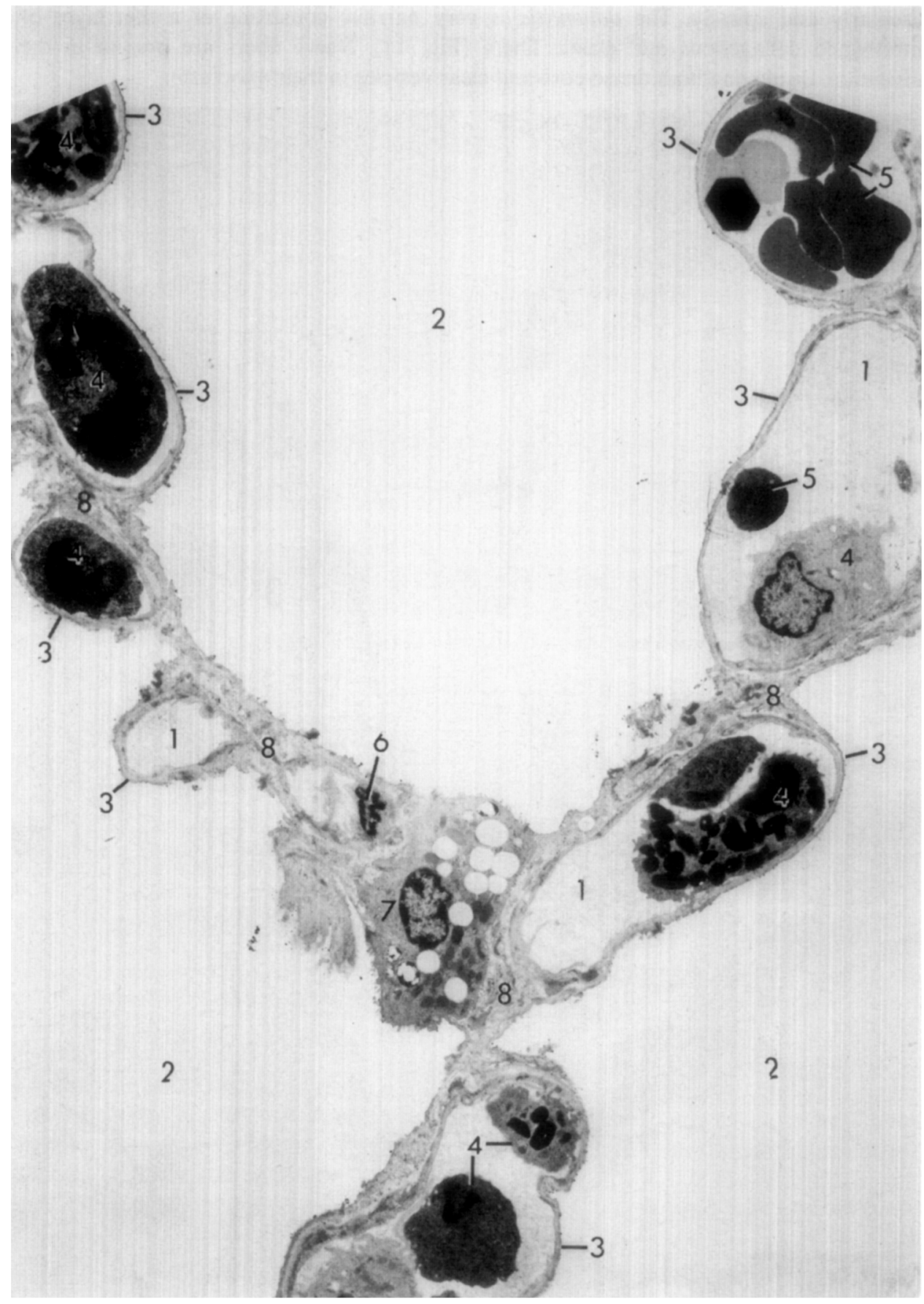

FIG. 15. Survey of interalveolar septa demonstrating the arrangement, density, and difference in size of pulmonary capillaries in the adult cat lung. Compare this micrograph with the diagrams in Figs. 5 and 6. Although the capillaries (1) border on adjacent alveoli (2), it should be noted that, in this field of view, there is a tendency for the capillaries to protrude only into one alveolus, and to present the thinnest part (3) of the 


\section{Precapillary Sphincter Area}

The pulmonary arterioles gradually give rise to terminal arterioles, which, considered from a functional point of view, can be referred to as the precapillary sphincter area. The luminal diameter of the precapillary sphincter area ranges between 30 and $160 \mu \mathrm{m}$ (Figs. 13 and 14). The wall of these microvessels consists of a thin, squamous endothelium, one to two layers of fiat smooth muscle cells, and a thin peripheral adventitial cuff of collagenous or elastic fibers in which occasional nerve fibers are also present. The endothelial cells are separated from the smooth muscle cells by a basal lamina without elastic fibers. Occasional small cell processes extend across the basal lamina from endothelial cells or smooth muscle cells to form myoendothelial junctions (Fig. 24). Just before the branching of the terminal arterioles into pulmonary capillaries, the smooth muscle cells form an incomplete layer, which disappears once the capillaries break up to form the dense network within the interalveolar septa.

\section{Pulmonary Capillaries}

The pulmonary capillaries average $5-10 \mu \mathrm{m}$ in luminal diameter. They are located in the interalveolar septa, and the same capillary may therefore be available for gas exchange in relation to several adjoining alveoli. The capillaries form a very dense network within the interalveolar septa. The spaces in this network are often smaller than the diameters of the capillaries themselves (Fig. 15). The capillary wall consists of an endothelium, a basal lamina, and the alveolar pneumocytes (granular, squamous) which line the inside of the alveoli. The endothelial cells of the pulmonary capillaries are not fenestrated, and contain only a small number of surface vesicles. Occasional pericytes are present at the connective tissue aspect of the endothelial cells, but they are not nearly as common as has been described for pulmonary capillaries of other species (Weibel, 1974).

Since the distribution and ultrastructure of pulmonary capillaries of several species has been described and discussed repeatedly over the past several years (Divertie and Brown, 1964; Weibel and Knight, 1964; Sobin et al., 1966; Schneeberger-Keeley and Karnovsky, 1968; Fung and Sobin, 1969; Weibel, 1969, 1973; Sobin et al., 1970; Rosenquist et al., 1973), there is no need to elaborate further on it in this communication. The general organization and distribution of blood capillaries in the cat lung can be seen in Fig. 15. The conceptual arrangement is depicted in Figs. 5 and 6.

\section{Postcapillary Venules and Pulmonary Venules}

Immediately adjacent to the alveolus, within the interalveolar septum, originate the postcapillary venules. These are short, stubby vessels with a diameter only slightly larger than that of the pulmonary capillaries (Figs. 16-18). The walls of the postcapillary venules contain occasional smooth muscle cells, which become more

capillary wall toward the air space. As always in the lung, the capillaries contain many types of leukocytes (4) in addition to the erythrocytes (5). Nuclei of squamous epithelial pneumocytes, fibroblasts, and pericytes arc not present at this level of scetioning, and there is only one nucleus of a capillary endothelial cell present (6). The cell in the center, facing two pulmonary alveoli (2), is a granular pneumocyte (7). Note the limited amount of connective tissue fibers (8) in the interalveolar septa. Cat, E.M. $\times 2232$. 

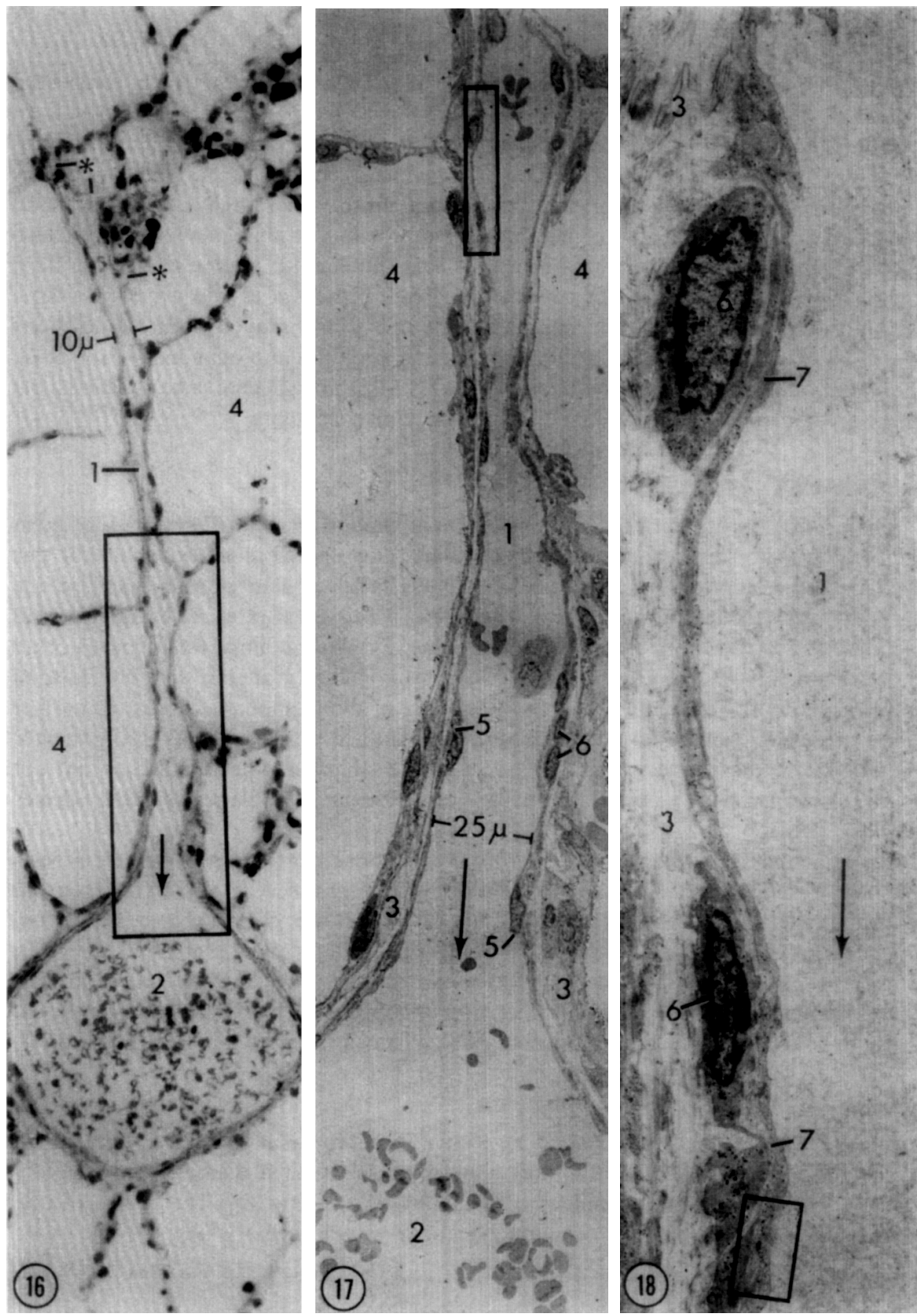

Figs. 16, 17, AND 18. Postcapillary venule and pulmonary venule in a series of stepwise-increased magnifications. Arrows indicate direction of blood flow. The areas indicated by rectangles are enlarged in subsequent micrographs. The venular system takes its origin from the alveolar capillaries at the asterisks (*), and the postcapillary venule (1) gradually increases in luminal size from 10 to $25 \mu \mathrm{m}$, connecting with a 
numerous as the postcapillary venule continues and enlarges in diameter as the pulmonary venule (Figs. 19-23). The observation that these venous channels are provided with true smooth muscle cells is new and, perhaps, somewhat unexpected. Furthermore, the smooth muscle cells make extensive membranous contacts with the endothelial cells in forming myoendothelial junctions much larger than those observed in the pulmonary arterioles (Figs. 23 and 25). The perivascular cells are definitely smooth muscle cells, and do not represent pericytes (Rouget cells) since they do contain distinct bundles of filaments, presumably myofilaments, in their cytoplasm.

\section{Small Pulmonary Veins}

These vessels range in size between about 50 and $1000 \mu \mathrm{m}$. The pulmonary venules increase gradually in size from 10 to about $50 \mu \mathrm{m}$ and, as such, join up gradually with other venules to form increasingly larger veins, or $50-\mu \mathrm{m}$-wide venules may join a 200 to $300-\mu \mathrm{m}$ vein (Figs. 19 and 20 ) at right angles.

The intima consists of squamous endothelial cells, rich in specific endothelial granules, surface vesicles, and microfilaments. The media consists of two to five layers of widely spaced smooth muscle cells which are arranged both circularly and longitudinally (Fig. 26). Thick bundles of collagen, mixed with some elastic fibers, separate the smooth muscle cells. The smooth muscle cells make lateral contacts, but also make connections with other cell layers. There are areas of extensive contacts with the endothelial cells via myoendothelial junctions. The adventitia contains some fibroblasts and occasional nonmyelinated nerves, as well as elastic fibers which form an incomplete outer elastic lamina.

\section{DISCUSSION}

Several investigators have studied the pulmonary circulation in vivo. Based on their observations, particularly the reports by Wearn et al. (1934) and Kniseley (1960), on the microcirculation of the cat lung, it is now possible and appropriate to correlate many of their functional observations with our detailed ultrastructural findings, the latter based on accurate determination of the precise size and structure of the various segments of arterial and venous blood vessels and their topographic relationship to other segments of the microvascular bed of the pulmonary alveoli of the cat's lung.

\section{Small Pulmonary Arteries and Veins}

The positive identification of the small pulmonary arteries and veins is an absolute necessity. In our investigation, this was done by finding both types of vessels in the same field (Fig. 1). The artery was near the respiratory passageway, whereas the vein

pulmonary venule (2) which has an average luminal diameter of $200 \mu \mathrm{m}$. The postcapillary venule (1) travels in the connective tissue (3) between two alveolar sacs (4). The nuclei of the endothelial cells of the venule (5) protrude into the lumen. However, at other points the protrusions are caused by smooth muscle cells (6) which form an incomplete layer, probably arranged in a spiral around the venular lumen. The smooth muscle cells make extensive contacts (7) with endothelial cells (myoendothelial junctions). This can be seen to greater advantage in Fig. 23, which is an enlargement of an area similar to the one indicated in Fig. 18. The presence of smooth muscle cells in postcapillary venules of the cat lung is described here for the first time. Cat: Fig. 16, L.M. $\times 176$; Fig. 17, E.M. $\times 540$; Fig. 18, E.M. $\times 4500$. 

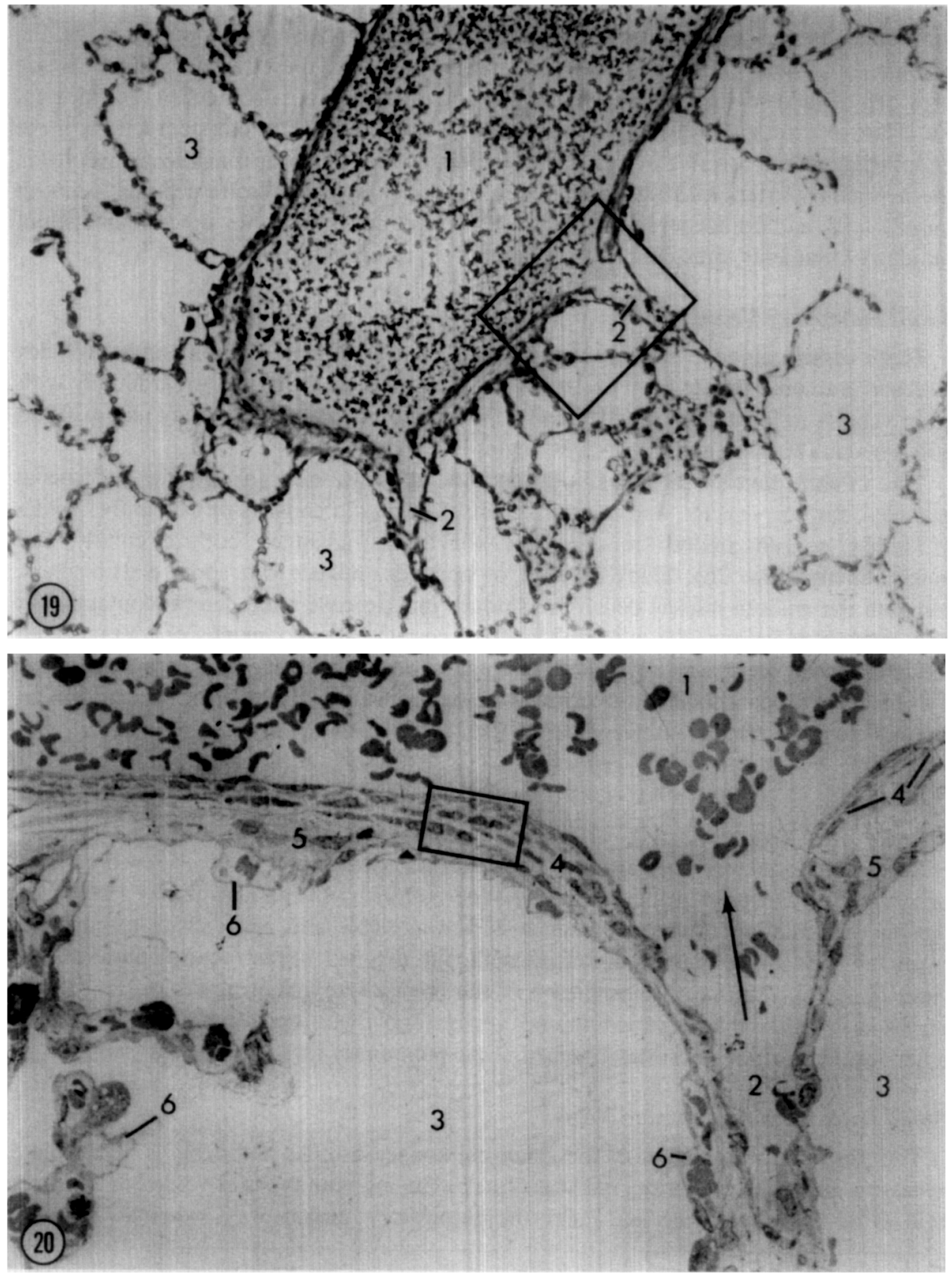

FIGS. 19 AND 20. Pulmonary venules and small pulmonary vein in a series of stepwise-increased magnifications. The area indicated by a rectangle in Fig. 19 is enlarged in Fig. 20. Arrow indicates direction of blood flow. The lumen of the small pulmonary vein (1) averages $250 \mu \mathrm{m}$ in width, whereas the lumens of the pulmonary venules (2) measure about $55 \mu \mathrm{m}$ at the point of their inlet. Note that the small pulmonary vein (1) occurs singly among the pulmonary alveoli (3). It has a muscular media (4) which varies greatly in thickness. This is also the case with the adventitia (5). Pulmonary capillaries (6) are present in the walls of the alveoli and the interalveolar septa. Area corresponding to the rectangle is enlarged in Fig. 26. The pulmonary venule in Fig. 20 is enlarged in its entirety or partially in Figs. 21, 22, and 23. Cat: Fig. 19, L.M. × 153; Fig. 20, E.M. $\times 540$. 


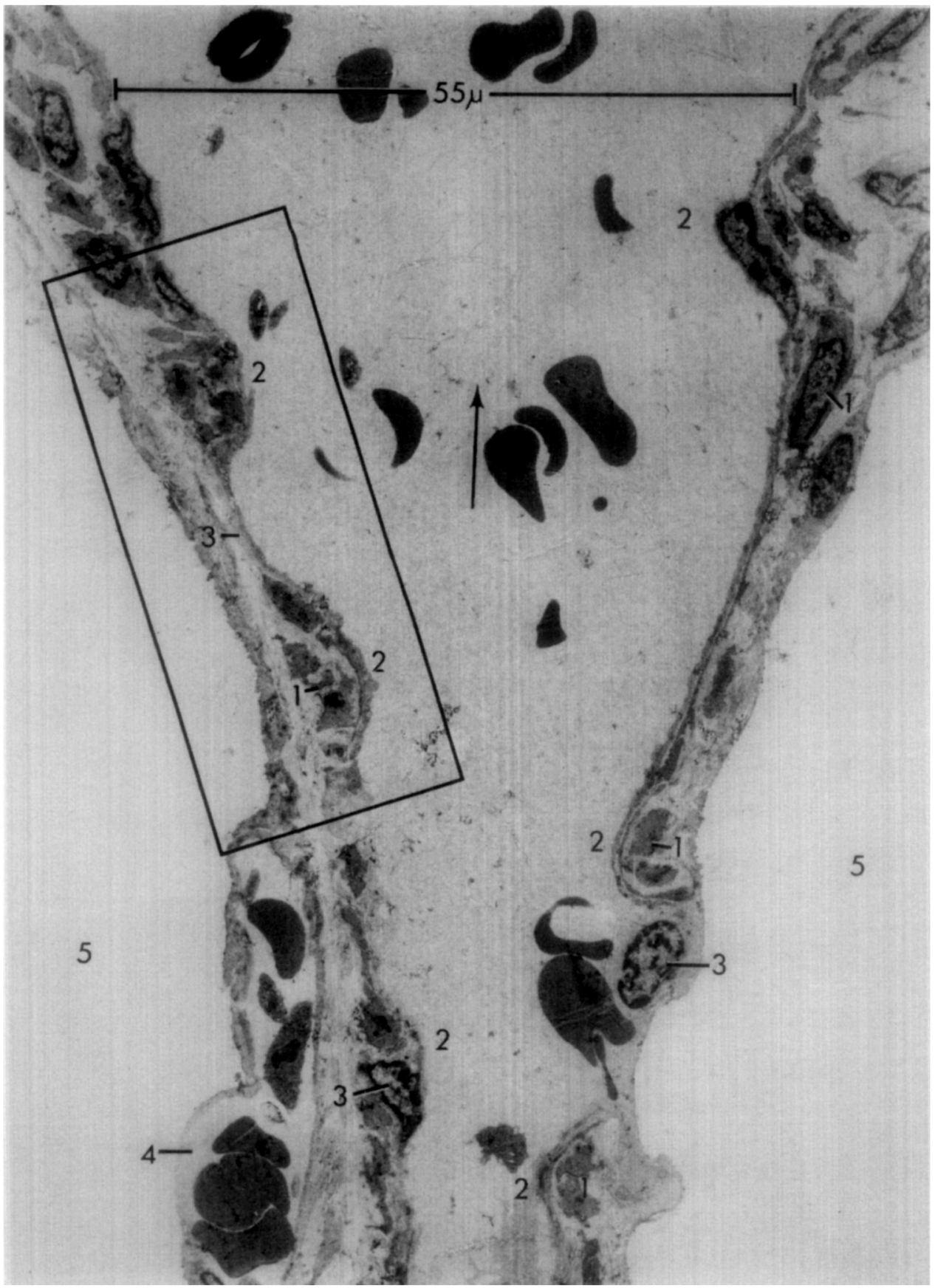

FIG. 21. Pulmonary venule. Enlargement of the same venule seen in Fig. 20. Arrow indicates direction of blood flow. The wall of the venule is characterized by scattered smooth muscle cells (1) which probably form a spiral. Because of a slight contraction of these smooth muscle cells, the wall of the venule protrudes into the lumen of the blood vessel with cushion-like formations (2). In the intervening areas, the endothelial cells (3) represent the only component of the vascular wall except for the basal lamina. A pulmonary capillary (4) lines the wall of the pulmonary alveolus (5). Area corresponding to the rectangle is enlarged in Fig. 22. Cat, E.M. $\times 1674$. 

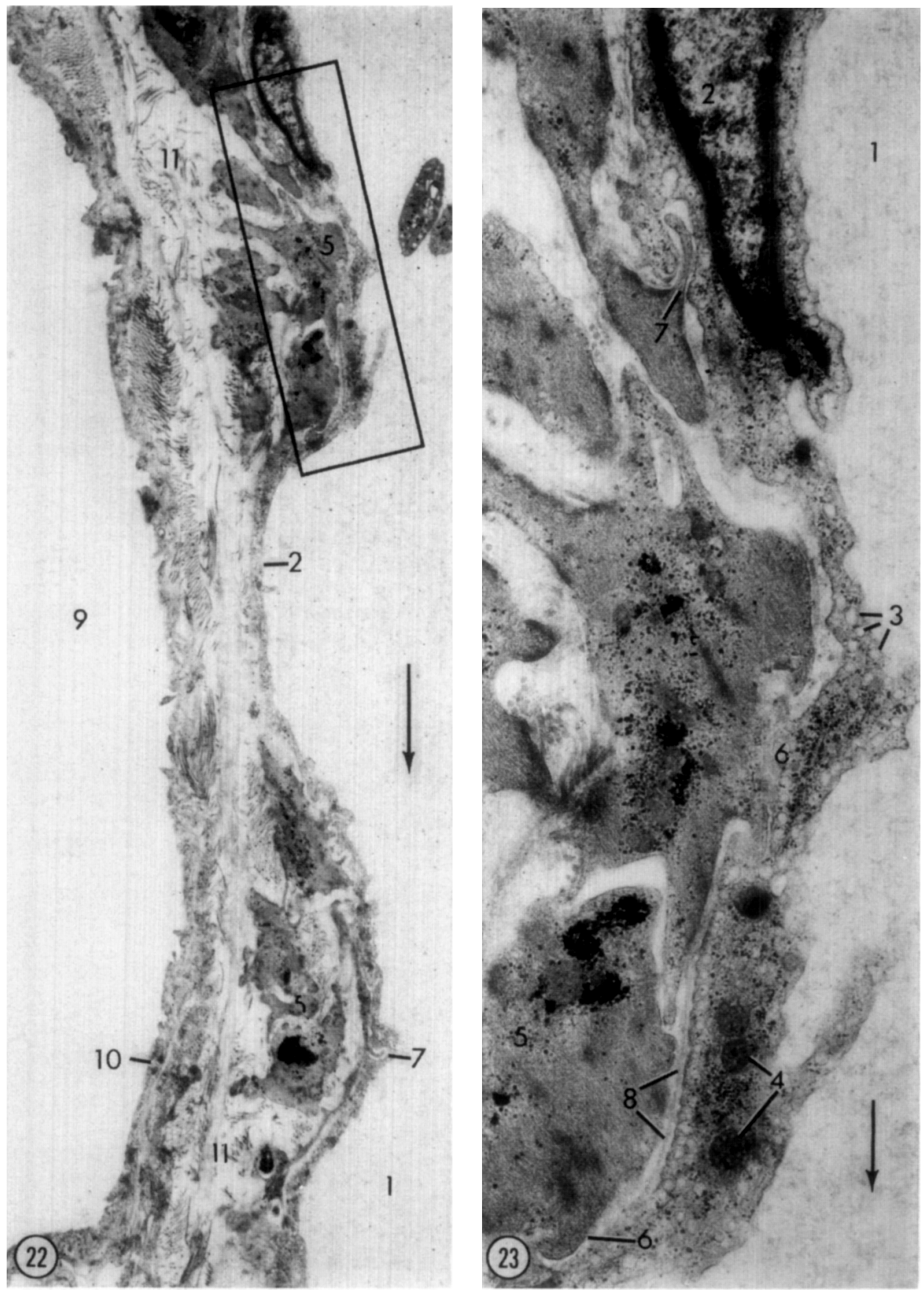

FIGS. 22 AND 23. Details of pulmonary venule. Enlargements of area outlined by a rectangle in Fig. 21. The area outlined in Fig. 22 is enlarged in Fig. 23. This enables one to follow the same pulmonary venule through a stepwise-increased magnification from $\times 153$ (in Fig. 19) to $\times 18,450$ (in Fig. 23). Arrows indicate direction of blood flow. The endothelial cells (2) bordering on the venular lumen (1) contain many pinocytotic surface vesicles (3) and specific endothelial granules (4). The protrusions of the venular wall into 
occurred at some distance from the artery. The ultrastructural analysis of the bronchial arteries compared to the pulmonary artery of the cat lung has appeared elsewhere (Rhodin, 1974). The difference between the pulmonary artery and its accompanying bronchial arteries relates mainly to the smaller overall size of the latter, the smaller luminal diameter, and the wall of the vessel which is proportionally thicker than that of the pulmonary artery.

Species differences in relation to the architecture of pulmonary arteries and veins can be recognized at the light-microscope level, as demonstrated by Best and Heath (1961) in their histological analysis of small pulmonary blood vessels in uninflated postmorten specimens from several mammals, excluding man. Perhaps still the most confusing situation persists in relation to several conflicting reports, indicating that, on the one hand, pulmonary arteries in the guinea pig (Verloop, 1949), rat (Verloop, 1949; Policard et al., 1965), and cattle (Hecht et al., 1959, 1962) contain a spirally arranged muscular media which, in longitudinal sections, appears as sphincter-like protrusions, or cushions, toward the vascular lumen. On the other hand, some authors describe the muscular media of the small pulmonary veins in cattle (Best and Heath, 1961; Alexander and Jensen, 1963) as having discontinuities which give the impression of sphincters. In the small arteries and veins of the cat lungs, there are no such sphincterlike protrusions. However, in some venules of our material, small cushions of smooth muscle cells occur at regular intervals (Figs. 18 and 22). Similar structures were not present in the arterioles. The sphincter-like protrusions are much more pronounced in the venules of the rat, and particularly in the small veins (Rhodin, unpublished observation). However, it seems that, in the guinea pig, according to Best and Heath (1961), the mediae of both pulmonary arteries and veins have a beaded appearance in longitudinal sections.

At the ultrastructural level in the cat lung, there is no difficulty in differentiating between small pulmonary arteries and veins, even without the knowledge of their topographic relationship to the respiratory passages (Figs. 3 and 26). The dense packing of the smooth muscle cells of the pulmonary arteries and the presence of both an inner and an outer elastic lamina in the pulmonary arteries stand in sharp contrast to the widely separated smooth muscle cells of the pulmonary veins, and the absence of a distinct inner elastic lamina. Another difference, although subtle, is the greater abundance of specific endothelial granules (Weibel and Palade, 1964) in the endothelial cells of the small pulmonary veins.

This investigation demonstrates that nonmyelinated nerve fibers are present in the adventitia of both small pulmonary arteries and veins in the cat lung (Figs. 3 and 14). A similar situation has been described by Fillenz (1970) in the dog lung. In both cat and $\mathrm{dog}$, it was found that the nerve fibers of the arteries were both cholinergic and noradrenergic. The former contain vesicles, averaging $500 \AA$ in width, whereas the noradrenergic fibers are associated with several populations of vesicles $(500-1000 \AA)$,

the vascular lumen are caused by groups of smooth muscle cells (5) which are arranged in a spiral around the vessel. The smooth muscle cells are highly branched and make numerous contacts (6) with the endothelial cells (myoendothelial junctions) which sometimes take the form of indentations (7). A thin basal lamina (8) is present in some areas. The pulmonary alveolus (9) is lined by a thin squamous epithelium (10) separated from the venule by its thin connective tissue adventitia (11). Cat: Fig. 22, E.M. ×4590; Fig. 23, E.M. $\times 18,450$. 

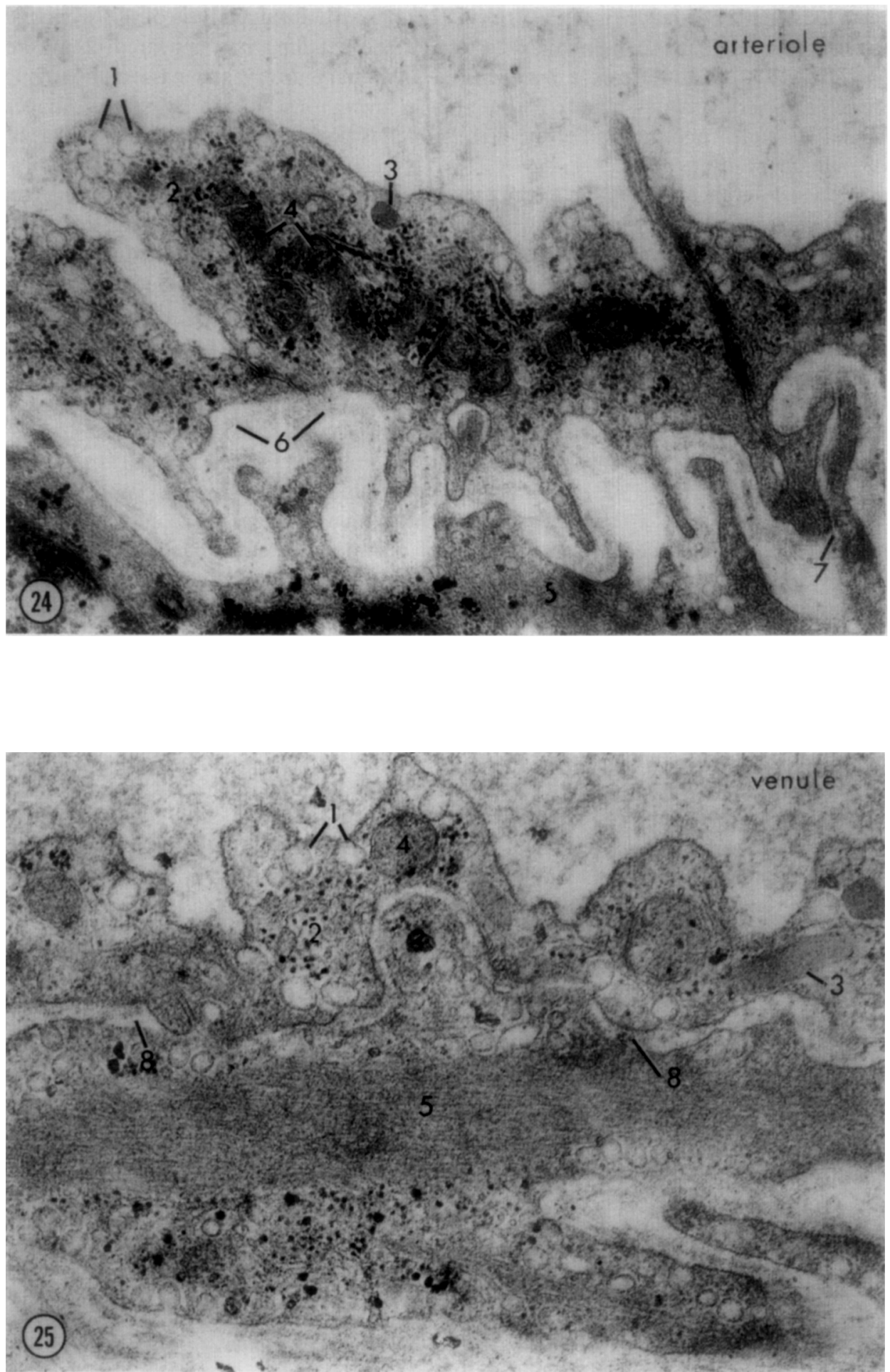
some of which have an electron-dense core, and others which are characterized by a moderately electron-dense core. The nerves remain largely in the adventitia, near the outer smooth muscle layer of the media. In no instance did the nerve fibers contact smooth muscle cell membrane, or penetrate in between the smooth muscle cells of the media. There is no doubt that the vasomotion of the small pulmonary arteries of the cat lung are under nervous control. However, the presence of myoendothelial junctions, representing contacts between endothelial cells and smooth muscle cells of the media, may facilitate the routing of blood-borne vasoactive hormones via these junctions, which contain gap junctions, to the smooth muscle cells. It is particularly noteworthy that the myoendothelial junctions are very extensive in the small pulmonary veins.

\section{Pulmonary Arterioles and Venules}

The differentiation between pulmonary arterioles and venules is difficult at the ultrastructural level without the knowledge of their direct connection to other segments of the pulmonary vessels. Based on our findings, it can now be firmly established that pulmonary arterioles in the cat contain smooth muscle cells down to and within the precapillary sphincter area. By light microscopy, several investigators identified smooth muscle cells in the pulmonary arterioles of man (von Hayek, 1940), cattle (Alexander and Jensen, 1963), and rabbit (Hirsch, 1957), whereas Krahl (1962) did not report them in the rat. By electron microscopy, Fillenz $(1966,1970)$ demonstrated the presence of smooth muscle cells in the dog pulmonary arterioles, and Policard et al. (1965) in the rat. Furthermore, we have confirmed the findings by Fillenz $(1966,1970)$ in the dog that the arterioles in the cat lung are, indeed, innervated by both cholinergic and nonadrenergic fibers.

The identification of postcapillary venules and pulmonary venules can be based on the fact that these vessels are provided with widely spaced smooth muscle cells which have extensive myoendothelial junctions with no intervening basal lamina (Fig. 25). This is in contradistinction to the pulmonary arterioles, which usually have a distinct basal lamina and short, narrow cell processes extending from either the endothelial cell or the smooth muscle cell, or both, establishing point-like myoendothelial junctions (Fig. 24). This is also in variance with the situation in the dermal microvessels of the rabbit (Rhodin. 1967, 1968), where the myoendothelial junctions of the arterioles are more extensive than those present in the venules. The observation that even postcapillary venules are provided with some smooth muscle cells is reported here for the first time. The pulmonary venules, therefore, differ from the venules of the dermal circulation, where true smooth muscle cells occur first in venules which have

FIGs. 24 AND 25. Details of terminal pulmonary arteriole (Fig. 24) and pulmonary venule (Fig. 25). In both cases, the endothelium contains pinocytotic surface vesicles (1), ribosomes (2), specific endothelial granules (3), and mitochondria (4). The smooth muscle cells contain bundles of myofilaments (5). The main difference between the architectural arrangement of the arteriole and the venule relates to the contacts between the endothelial and smooth muscle cells (myoendothelial junctions). In the arteriole, the endothelial and smooth muscle cells both have short, narrow, finger-like processes which traverse the subendothelial space and its basal lamina (6) to make point-like contacts (7), whereas, in the venule, the endothelial and smooth muscle cells make extensive contacts (8) with no intervening basal lamina. These extensive myoendothelial junctions are believed to facilitate ionic and nutritional communications between the endothelial cells and the smooth muscle cells. They may represent a possible route for blood-borne neurotransmitters to reach the smooth muscle cells. Cat: Fig. 24, E.M. $\times 30,690$; Fig. 25, E.M. $\times 35,340$. 


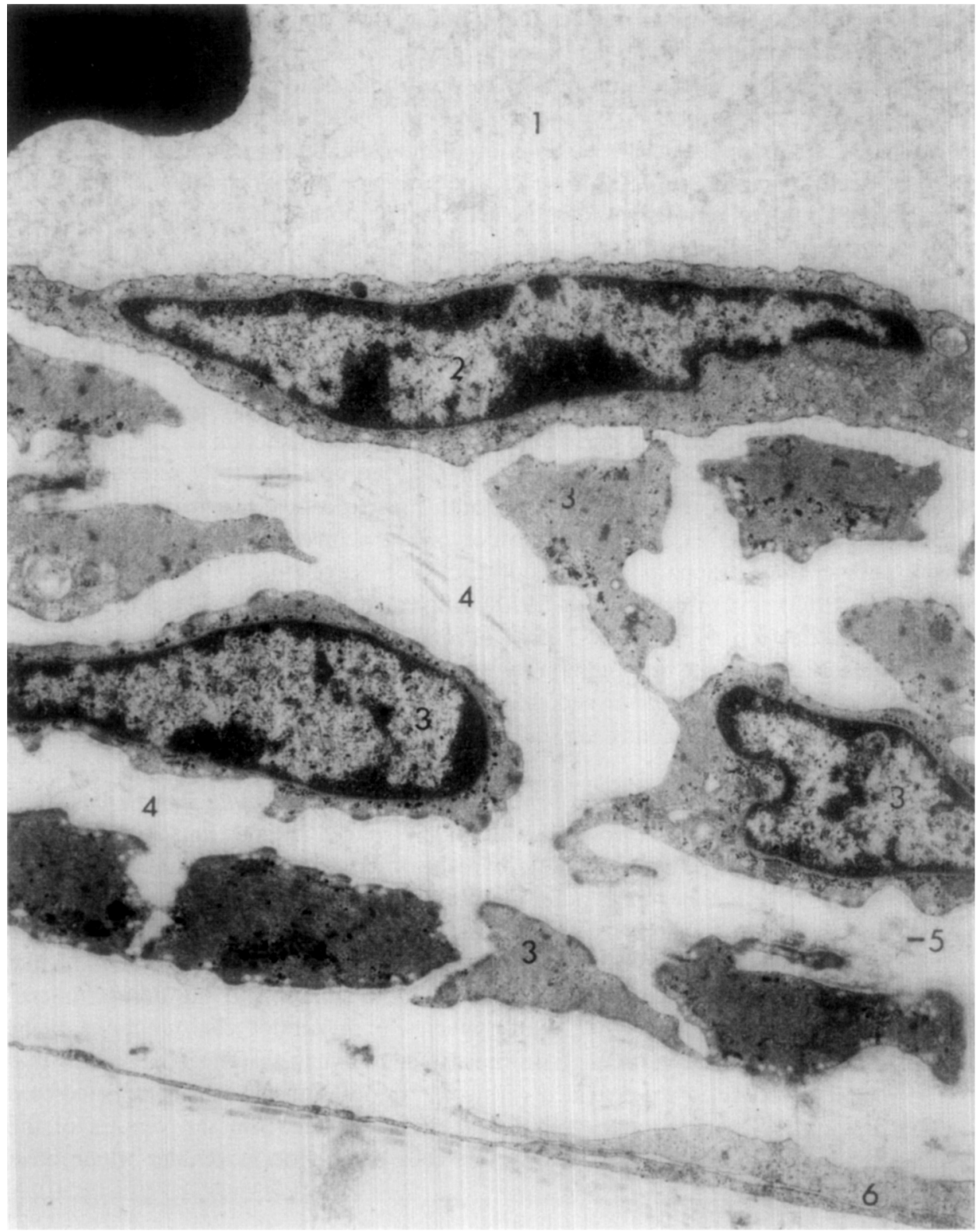

Fig. 26. Detail of the wall of a small pulmonary vein. Enlargement of area similar to rectangle in Fig. 20. This micrograph should be compared with Fig. 3, where a similar area of a small pulmonary artery can be seen. The lumen of the vein (1) is lined by squamous endothelial cells (2) with no distinct elastic lamina toward the smooth muscle cells (3) of the media. These cells are separated rather widely by many collagenous (4) and some elastic (5) fibers. The adventitia is delicate, and, in this area, contains only thin strands of fibroblasts (6). For a comparison of arterial and venous walls of small pulmonary vessels, turn to Fig. 3. Cat, E.M. $\times 9975$. 
attained a diameter of about $50 \mu \mathrm{m}$. Earlier light-microscope investigations have failed to recognize this feature of postcapillary venules (Macklin, 1945; Alexander and Jensen, 1963; Best and Heath, 1961), which is understandable considering the resolution of the light microscope. We are positive that these cells are smooth muscle cells and not pericytes, based on our extensive analysis of pericytes in dermal venous capillaries and postcapillary venules (Rhodin, 1968), and on the analysis by Weibel (1974) of pericytes associated with pulmonary capillaries in the rat lung.

From a functional point of view, Wearn et al. (1934) observed repeatedly in their in vivo studies that the pulmonary arterioles and terminal arterioles (precapillary sphincter area) of the cat lung contract actively and with great variation, since at a given moment of observation one branch would be dilated and the other branch constricted. They also observed reversal of the direction of blood flow in some arterioles. It is also obvious from the findings by Irwin et al. (1954) in their in vivo observations in the guinea pig and rabbit that pulmonary arterioles and venules change their diameters considerably, ranging between 30 and $160 \mu \mathrm{m}$ when observed over a prolonged period of time. These changes of vessel diameter were believed to reflect active vascular contraction which seemed to have no direct relation to the respiratory movements of the lung or the rib cage. Our findings support these in vivo observations, since we have demonstrated in the cat that pulmonary arterioles, as well as postcapillary venules and pulmonary venules, are provided with smooth muscle cells which, in the case of the venous vessels, are in extensive membranous contact with the endothelial cells. It could be that the pulmonary venous system is more susceptible to blood-borne neurotransmitter substances than is the dermal venous system. Our finding that the myoendothelial junctions are more numerous in the pulmonary venules than in the arterioles, and our finding of the paucity of nerves and nerve endings in relation to the pulmonary venules, are also in support of the findings and hypothesis by Irwin et al. (1954) that the intermittence of blood flow observed by them in small pulmonary vessels depends on local action of smooth muscle cells, rather than on some neural action. Also, Wearn et al. (1934) postulated that the intermittence of blood flow observed by them in the pulmonary capillaries of the cat could be due to slight changes of the pressure in the pulmonary microcirculation.

Although Wiggers (1921) and Macklin (1945) pointed out that the intrapulmonary vessels are mechanically dilated at the beginning of inspiration, but tend to be compressed toward the end of this respiratory phase, Wiggers (1921) recognized that a change in the total resistance within the pulmonary circuit is the result of a changing capacity of the extra- and intrapulmonary arteries and branches, as well as the changing resistance of the smaller arterioles and capillaries and the changing venous and left auricular pressures. Brody et al. (1968) demonstrated that the pulmonary arteries and arterioles are responsible for $46 \%$ of the total lobar vascular resistance, whereas the pulmonary capillaries and veins account for 35 and $20 \%$ of total lobar vascular resistance, respectively. In addition. Brody and Stemmler (1968) demonstrated that histamine infusion caused predominantly venous constriction. There was a slight constriction of the large arterial vessels, whereas the small arterial vessels appeared to be possibly dilated.

It seems reasonable, therefore, to assume that the presence of smooth muscle cells throughout the venous vessels of the cat lung and the intimate contact between smooth 
muscle cells and endothelial cells may represent the structural basis for the possibility that an active contraction can take place in response to blood-borne vasoactive hormones. In most instances, it is assumed that an arterial vasospasm, smooth mucle hyperplasia, or obstruction is the most frequent cause of pulmonary hypertension (Edwards, 1974). However, a pulmonary venous occlusion, perhaps initiated by vasospasm, may also be a contributory factor in the development and progression of pulmonary hypertension, particularly in view of the discovery reported here that postcapillary venules and pulmonary venules are, indeed, provided with smooth muscle cells in the lung of the cat. Furthermore, since the blood pressure of the pulmonary venous system is lower than that in the veins of the systemic circulation, only a very slight constriction of the venules would result in an increased resistance.

\section{ACKNOWLEDGMENTS}

This study was supported by NIH Grants HL18021 and HL 18831-01. The skillful technical assistance by Miss Shirley Lim Sue, and the constructive and helpful assistance in the preparation of the drawings by Mr. William L. Brudon are greatly appreciated.

\section{REFERENCES}

ALEXANDER, A. F., AND JENSFN, R. (1963). Normal structure of bovine pulmonary vasculature. Amer. $J$. Vet. Res. 24, 1083-1093.

BEST, P. V., AND HEATH, D. (1961). Interpretation of the appearances of the small pulmonary blood vessels in animals. Circ. Res. 9, 288-294.

Brody, J. S., AND Stemmler, E. J. (1968). Differential reactivity in the pulmonary circulation. J. Clin. Invest. 47, 800-808.

Brody, J. S., Stemmler, E. J., AND Dubols, A. B. (1968). Longitudinal distribution of vascular resistance in the pulmonary arteries, capillaries and veins. J. Clin. Invest. 47, 783-799.

COMroE, J. H. (1966). The main functions of the pulmonary circulation. Circulation 33, 146-158.

Daly, I. D. B., AND HeBB, C. (1966). "Pulmonary and Bronchial Vascular Systems," 1st ed. Williams \& Wilkins, Baltimore.

DIVERITE, M. B., AND BRoWN, A. L. (1964). The fine structure of the normal human alveolocapillary membrane. J. Amer. Med. Assoc. 187, 938-941.

EDWARdS, J. E. (1974). Pathology of chronic pulmonary hypertension. Pathol. Annu. 9, 1-25.

FILLENZ, M. (1966). Innervation of blood vessels of lung and spleen. Bibl. Anat. 8, 56-59.

FILLENZ, M. (1970). Innervation of pulmonary and bronchial vessels of the dog. J. Anat. 106, 449-461.

Fishman, A. P., AND HeChT, H. H. (1969). "The Pulmonary Circulation and Interstitial Space." Univ, of Chicago Press, Chicago.

Fung, Y. C.. AND Sobin, S. S. (1969). Theory of sheet flow in lung alveoli. J. Appl. Physiol. 26, 472-488.

Hecht, H. H., Lange, R. L., Carnes, W. H., Kuida, H., and Blake, J. T. (1959). Brisket Disease. I. General aspects of pulmonary hypertensive heart disease in cattle. Trans. Assoc. Amer. Phys. 72, 157172.

Hecht, H. H., Kuida, H., Lange, R. L., Thorne, J. L., And Brown, A. M. (1962). Brisket Disease. II. Clinical features and hemodynamic observations in altitude-dependent right heart failure of cattle. Amer. J. Med. 32, 171-183.

HiRsch, S. (1957). Sur les caractéristiques histologiques des petits vasseaux pulmonaires. Experientia 13, $145-147$.

Irwin, J. W., Burrage, W. S., Aimar, C. E., and Chestnut, R. W., JR. (1954). Microscopical observations of the pulmonary arterioles, capillaries, and venules of living guinea pigs and rabbits. Anat. Rec. 119, 391-408.

KraHL, V. E. (1959). Microscopic anatomy of the lungs. Amer. Rev. Resp. Dis. 80, part II, 24-40.

KRAHL, V. E. (1962). Relationships of peripheral pulmonary vessels to the respiratory areas of the lung. Med. Thoracalis 19. 194-207. 
KNISELy, W. H. (1960). In vivo architecture of blood vessels supplying and draining alveoli. Amer. Rev. Resp. Dis. 81, 735-736.

LAUWERYNS, J. M. (1971). The blood and lymphatic microcirculation of the lung. Pathol. Annu. 6, 365415.

LieBow, A. A., AND SMITH, D. E. (1968). "The Lung." Williams \& Wilkins, Baltimore.

MACKLIN, C. C. (1945). Terminal pulmonary venules in mammalian lungs Roy. Soc. Canada 39 (V), 105130.

Merkel, H. (1940). Zur Histologie der Lungengefässe. Beitr. Pathol. Anat. 105, 176-202.

Policard, A., AND GALY, P. (1970). "L'Appareil Broncho-Pulmonaire. Structures et Mechanismes à l'État Normal et Pathologique." Masson, Paris.

Policard, A., Collet, A., ANd Martin, J.-C. (1965). Études d'histophysiologie pulmonaire. La microcirculation du poumon chez l'homme. Presse Med. 73, 1511-1517.

Pump, K. K. (1961). The circulation of the primary lobule of the lung. Dis. Chest 39, 614-621.

Rhodin, J. A. G. (1967). The ultrastructure of mammalian arterioles and precapillary sphincters. $J$. Ultrastruct. Res. 18, 181-223.

RHodiN, J. A. G. (1968). Ultrastructure of mammalian venous capillaries, venules, and small collecting veins. J. Ultrastruct. Res. 25, 452-500.

RhodiN, J. A. G. (1974). "Histology," 1st ed. Oxford Univ. Press, New York.

Rosenquist, T. H., Bernick, S., Sobin, S. S., AND Fung, Y. C. (1973). The structure of the pulmonary interalveolar microvascular sheet. Microvasc. Res. 5, 199-212.

SCHNEEBERGER-KeEley, E. E., AND KARNOVSKY, M. J. (1968). The ultrastructural basis of alveolarcapillary membrane permeability to peroxidase used as a tracer. J. Cell Biol. 37, 781-792.

Sobin, S. S., TREMER, H. M., AND Fung, Y. C. (1970). Morphometric basis of the sheet-flow concept of the pulmonary alveolar microcirculation in the cat. Circ. Res. 26, 397-414.

Sobin, S. S., Intaglietta, M., Frasher, W. G., and Tremer, H. M. (1966). The geometry of the pulmonary microcirculation. Angiology 17, 24-30.

VERLOOP, M. C. (1949). On the arteriae bronchiales and their anastomosing with the arteria pulmonalis in some rodents; A micro-anatomical study. Acta Anat. 7, 1-32.

von HAYEK, H. (1940). Über de Präcapillaren, die Arteriolen und die Teilungsstellen der kleinen Arterien in der menschlichen Lunge. Z. Anat. 110, 587-596.

W AALer, B. A. (1971). Physiology of the pulmonary circulation. Angiologica 8, 266-284 (138-156).

Wearn, J. T., ERnstene, A. C., Bromer, A. W., BarR, J. S., German, W. J., AND Zschiesche, L. J. (1934). The normal behavior of the pulmonary blood vessels with observations on the intermittence of the flow of blood in the arterioles and capillaries. Amer. J. Physiol. 109, 236-256.

WeIBEL, E. R. (1969). Ultrastructure of the alveolar-capillary membrane or barrier. In "Pulmonary Circulation and Interstitial Spaces" (A. Fishman and H. H. Hecht, eds.), pp. 9-27. Univ. of Chicago Press, Chicago.

WEIBEL, E. R. (1973). Morphological basis of alveolar-capillary gas exchange. Physiol. Rev. 53, 419495.

WEIBEL, E. R. (1974). On pericytes, particularly their existence on lung capillaries. Microvasc. Res. 8, 218-235.

WEIBEL, E. R., AND KNIGHT, B. W. (1964). A morphometric study on the thickness of the pulmonary airblood barrier. J. Cell Biol. 21, 367-384.

Weibel, E. R., AND Palade, G. E. (1964). New cytoplasmic components in arterial endothelia. J. Cell Biol. 23, 101-112.

WIGGERS, C. J. (1921). The regulation of the pulmonary circulation. Physiol. Rev. 1, 239-268. 